Journal of Mathematics and Statistics 7 (3): 222-226, 2011

ISSN 1549-3644

(C) 2011 Science Publications

\title{
Effect of Activation Energies on Thermal Explosion in the Interior of the Earth
}

\author{
Amos Oladele Popoola \\ Department of Mathematical and Physical Sciences, \\ College of Science, Engineering and Technology, \\ Osun State University, Osogbo Nigeria
}

\begin{abstract}
Problem statement: Literatures have shown that thermal processes in the interior of the earth and the classical thermal explosion are analogous and that combustion processes are characterized by ignition and explosion. The heat released during the thermal explosion that occurs in the interior of the earth requires more attention. Approach: The study investigated the role of activation energies ratio in the thermal explosion that occurs in the earth interior during gravitational differentiation. The study examined the effects of activation energies on the unsteady, steady and homogenous reactions of the resulting energy equation and provided the numerical and exact solutions of the equations. Results: The results showed that activation energies ratio has different implication in terms of heat release and established the criteria for the blow up to occur in two different homogenous reactions. It was observed that an increase in activation energies ratio increased the maximum temperature of the reactions but reduced the ignition time of the homogenous states. Conclusion: The results imply that for any non-zero second activation energy, ignition time lowers and more heat are released.
\end{abstract}

Key words: Homogenous reaction, thermal explosion, activation energy, Gravitational Differentiation (GD), Blow up, dimensionless temperature, activation energy ratio, decay of radioactive, exothermic reaction, chemical decomposition

\section{INTRODUCTION}

Earthquake is a recent natural disastrous occurrence in some parts of the world and this requires more scientific attention and knowledge. One of the causes of earth quake is the ignition of underground hydrocarbons (methane gas (McDonald, 2005)) in the interior of the earth. The ignition source is activated during gravitational differentiation and when the gaseous heated materials come in contact with magma, it may lead to explosion. Thus, the energy which triggers the process is the activation energy which is the energy which the colliding molecules must possess before the ignition could result into a reaction.

Some scientific literatures have shown that most combustion problems are characterized by two processes; Ignition and Explosion; and some of the useful results on classical thermal explosion are recently obtained in (Kannan and Udayakumar, 2009). Meanwhile, thermal processes occur in the earth interior, although differ from characteristic thermal explosion but according to (Vityazev, 2004; Barenblatt, 1985) they are analogous. There are many sources of heat in the interior of the earth but two major sources constitute the exothermic regimes; the Gravitational Differentiation (GD) and the decay of radioactive elements.

Explosion generally results from two exothermic reactions; one step follows the other in very rapid succession depending on the activation energies of the reactions has equally shown that although multiple steps are involved in chemical reaction but two major steps are basically involved and these include chemical decomposition and combustion process. The first activation energy is for decomposition while the other is meant for combustion. This implies that during the earth movement chemical decomposition and combustion takes place in the presence of activation energies.

Having been motivated by (Ayeni et al., 2006; Vityazev, 2004) in their work on thermal explosion in the evolution of the earth and for which they considered only one activation energy for the entire process. This study therefore extends their work by breaking the activation energy into two; one for decomposition and the other for combustion. And the study examines the role of these activation energies in unsteady, steady and homogenous states during gravitational differentiation. 
Following (Buckmaster et al., 2008), the criteria for the blow up to occur in the homogenous reaction even when no heat is generated from the decaying of radioactive substance, are established.

Problem Statement: Following (Ayeni et al., 2006; Vityazev, 2004), a model of sinking of heavy inclusions in a viscous matrix $\eta$ is considered. The thermal conductivity equation governing the generation of heat during GD and the decay of radioactive elements is given by (Ayeni et al., 2006; Vityazev, 2004):

$$
\rho \ell_{\mathrm{p}} \frac{\partial \mathrm{T}}{\partial \mathrm{t}}=\operatorname{div}\left(\lambda+\lambda_{\mathrm{d}}\right) \Delta \mathrm{T}+\varepsilon_{\mathrm{r}}+\varepsilon_{\mathrm{d}}
$$

Satisfying the initial and boundary conditions:

$$
\mathrm{T}(\mathrm{x}, 0)=\mathrm{T}_{0}, \quad \mathrm{~T}(-1, \mathrm{t})=\mathrm{T}(1, \mathrm{t})=\mathrm{T}_{0}
$$

where, $\varepsilon_{\mathrm{d}}$ and $\varepsilon_{\mathrm{r}}$ are the rate of generation of heat by GD and radioactive decay respectively. According to (Vityazev, 2004), the Stoke's mode of sinking of inclusions $\operatorname{Re}<<1, \varepsilon_{\mathrm{d}}$ is proportional to the flow of excess density $\varepsilon_{\mathrm{d}} \approx \mathrm{c}(1-\mathrm{c}) \Delta \rho g \mathrm{~V}_{\mathrm{d}}$, where $\mathrm{c}$ is the fraction of the volume occupied by inclusions $\mathrm{V}_{\mathrm{d}}=(1-2.5 \mathrm{c}) 2 \frac{\Delta \rho \mathrm{ga}^{2}}{9 \eta}$ is their velocity and $\eta$ is the viscosity defined by:

$$
\eta=\eta_{\mathrm{o}} \exp \left(\left(\mathrm{E}_{1}(\rho)+\mathrm{E}_{2}(\rho)\right) / \mathrm{RT}\right)
$$

where, $E_{1}$ and $E_{2}\left(E_{2}=\alpha E_{1}\right)$ respectively account for the two activation energies involved during decomposition and combustion processes and $\alpha$ is the ratio of the activation energies.

Remark 1: $\mathrm{E}_{2}(\rho)=0$ was considered by (Ayeni et al., 2006; Vityazev, 2004).

The following dimensionless parameters are introduced to Eq 1:

$$
\mathrm{T}=\mathrm{T}_{0}+\frac{\mathrm{RT}_{0}^{2} \theta}{\mathrm{E}_{1}}, \varepsilon=\frac{\mathrm{RT}_{0}}{\mathrm{E}_{1}}, \tau=\frac{4 æ}{\mathrm{~h}^{2}} \mathrm{t}, \mathrm{z}=\frac{\mathrm{h}}{2} \xi, \mathrm{E}_{2}=\alpha \mathrm{E}_{1}
$$

And for highly exothermic reaction, the Eq. 1 together with conditions (2) in a dimensionless form is:

$$
\frac{\partial \theta}{\partial \tau}=\frac{\partial}{\partial \xi}\left(1+\mathrm{P}_{\mathrm{eo}} \mathrm{e}^{\frac{(1+\alpha) \theta}{\mathrm{n}}}\right) \frac{\partial \theta}{\partial \xi}+\Gamma_{\mathrm{d}} \mathrm{e}^{(1+\alpha) \theta}+\Gamma_{\mathrm{r}}
$$

Together with the initial and boundary conditions:

$$
\theta(\xi, 0)=0, \quad \theta(-1, \tau)=\theta(1, \tau)=0
$$

Where:

$$
\Gamma_{\mathrm{r}}=\frac{\varepsilon_{\mathrm{r}} \mathrm{h}^{2} \mathrm{E}_{1}}{4 \lambda \mathrm{RT}_{\mathrm{o}}^{2}}, \Gamma_{\mathrm{d}}=\frac{\varepsilon_{\mathrm{d}} \mathrm{h}^{2} \mathrm{E}_{1}}{4 \lambda \mathrm{RT}_{\mathrm{o}}^{2}}=\frac{\Delta \rho \mathrm{gcv}_{\mathrm{o}} \mathrm{h}^{2} \mathrm{E}_{1}}{4 \lambda \mathrm{RT}_{\mathrm{o}}^{2}}
$$

Where:

$$
\begin{array}{ll}
\theta & =\text { Dimensionless temperature of the system } \\
\mathrm{p}_{\mathrm{e}} & =\text { Peclet number } \\
\varepsilon_{\mathrm{r}} \text { and } \varepsilon_{\mathrm{d}} & =\text { Rates of sinking of inclusion } \\
\lambda & =\text { Ordinary thermal conductivity } \\
\mathrm{R} & =\text { Universal gas constant } \\
\rho & =\text { Density } \\
\mathrm{g} & =\text { gravity } \\
\mathrm{T}_{0} & =\text { Initial temperature } \\
\mathrm{v}_{0} & =\text { Initial velocity } \\
\mathrm{h} & =\text { Thickness of a flat layer } \\
\mathrm{n} & =\text { Order of thermal conductivity }
\end{array}
$$

Remark 2: When $\alpha=0$, the unsteady equation formulated by (Vityazev, 2004) is obtained.

\section{MATERIALS AND METHODS}

The unsteady problem (5) satisfying initial and boundary condition (6) is solved by finite difference method with the scheme:

$$
\begin{aligned}
\theta_{i, j+1} & =\theta_{i, j}+\frac{k}{h^{2}}\left(1+P_{e o} e^{\frac{(1+\alpha) \theta_{i, j}}{n}}\right)\left(\theta_{i+1, j}-2 \theta_{i, j}+\theta_{i-1, j}\right) \\
& +\frac{k}{h^{2}}\left(\frac{P_{e o}}{n} e^{\frac{(1+\alpha) \theta_{i, j}}{n}}\right)\left(\theta_{i+1, j}-\theta_{i, j}\right)^{2}+k \Gamma_{d} e^{(1+\alpha) \theta_{i, j}}+k \Gamma_{r}
\end{aligned}
$$

Subject to the initial and boundary conditions:

$\theta_{i, 0}=0, \quad \theta_{\frac{-1}{h}, j}=\theta_{\frac{1}{h}, j}=0$

The numerical result as obtained through a computer programme written in Pascal language is presented in the Fig. 1. (6) is:

The homogeneous case of problem (5) satisfying

$$
\frac{\mathrm{d} \theta}{\mathrm{d} \tau}=\Gamma_{\mathrm{d}} \mathrm{e}^{(1+\alpha) \theta}+\Gamma_{\mathrm{r}}
$$

Subject to the initial condition:

$$
\theta(0)=0
$$




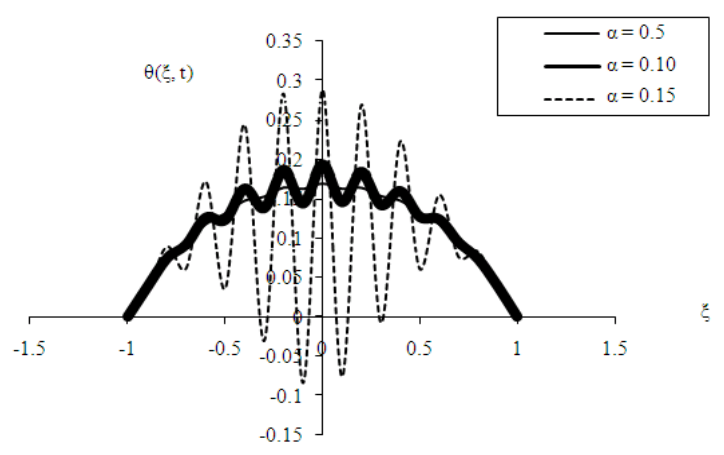

Fig. 1: Plot of the unsteady state temperature $\theta(\xi, t)$ for some values $\alpha>0$

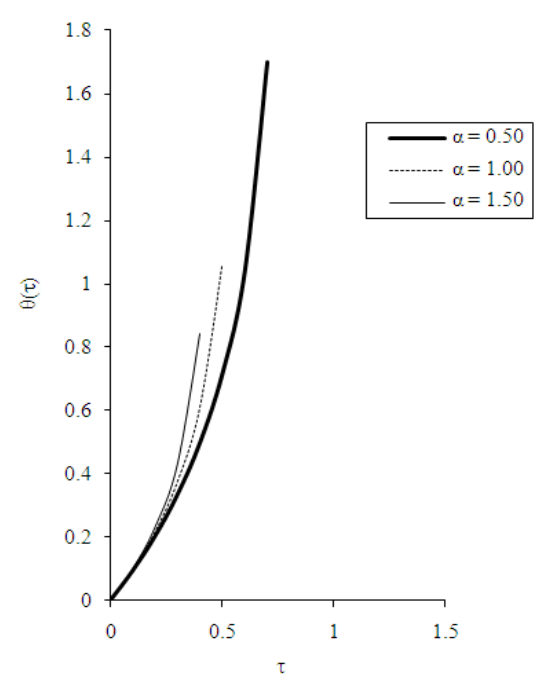

Fig. 2: The ignition temperature Profile for fixed values $\Gamma_{\mathrm{r}}=0, \Gamma_{\mathrm{d}}=0.878$ and various values of $\alpha$

Assume that $\Gamma_{\mathrm{r}}=0$, by the method of separation of variables, the exact solution of temperature together with blow up criterion is respectively presented as:

$$
\begin{gathered}
\theta=\frac{-1}{(1+\alpha)} \ln \left[1-(1+\alpha) \Gamma_{\mathrm{d}} \tau\right], \alpha>0 \\
\tau_{\infty}^{*}=\frac{1}{(1+\alpha) \Gamma_{\mathrm{d}}}, \quad \Gamma_{\mathrm{d}}>0, \alpha>0
\end{gathered}
$$

The graphical interpretation of (11) is presented in Fig. 2.

If $\Gamma_{\mathrm{r}} \neq 0$, then an analytical solution of ignition temperature is presented as:

$$
\theta=\frac{-1}{(1+\alpha)} \ln \left[\left(1+\frac{\Gamma_{\mathrm{d}}}{\Gamma_{\mathrm{r}}}\right) \mathrm{e}^{\frac{-\Gamma_{\mathrm{r}}}{(1+\alpha)}}-\frac{\Gamma_{\mathrm{d}}}{\Gamma_{\mathrm{r}}}\right]
$$

with the blow up criterion:

$$
\tau_{\infty}^{*}=\frac{(1+\alpha)}{\Gamma_{\mathrm{r}}} \ln \left(1+\frac{\Gamma_{\mathrm{r}}}{\Gamma_{\mathrm{d}}}\right), \quad \Gamma_{\mathrm{r}}, \Gamma_{\mathrm{d}} \neq 0, \alpha \geq 0
$$

The steady state of problem (5) satisfying (6) is given by:

$$
\begin{aligned}
& \frac{d}{d \xi}\left(1+p_{e} e^{\frac{(1+\alpha) \theta}{n}}\right) \frac{d \theta}{d \xi}+\Gamma_{d} e^{(1+\alpha) \theta}+\Gamma_{r}=0 \\
& \Rightarrow\left(1+P_{e 0} e^{\frac{(1+\alpha) \theta}{n}}\right) \frac{d^{2} \theta}{d \xi^{2}}+\left(\frac{(1+\alpha) P_{e 0}}{n} e^{\frac{(1+\alpha) \theta}{n}}\right)\left(\frac{d \theta}{d \xi}\right)^{2} \\
& +\Gamma_{d} e^{(1+\alpha) \theta}+\Gamma_{\mathrm{r}}=0
\end{aligned}
$$

Subject to the boundary condition:

$$
\theta(-1)=\theta(1)=0
$$

Existence and uniqueness: Following (Olajuwon and Popoola, 2006), the following theorems establish the criteria for the existence of unique steady solution.

Theorem 1: $\quad$ For $0 \leq \alpha \leq N,-1 \leq \mathrm{x}_{1} \leq 1$, $\mathrm{N}, \Gamma_{\mathrm{r}}, \Gamma_{\mathrm{d}}, \mathrm{n}, \mathrm{P}_{\mathrm{eo}}>0$, problem (16) which satisfies conditions (17) and for which $\theta^{\prime}(-1)$ is fixed, has a unique solution:

$$
\operatorname{Let}\left(\begin{array}{l}
\mathrm{x}_{1} \\
\mathrm{x}_{2} \\
\mathrm{x}_{3}
\end{array}\right)=\left(\begin{array}{l}
\xi \\
\theta \\
\theta^{\prime}
\end{array}\right)
$$

$$
\begin{aligned}
& \left(\begin{array}{c}
\mathrm{x}_{1}^{\prime} \\
\mathrm{x}_{2}^{\prime} \\
\mathrm{x}_{3}^{\prime}
\end{array}\right)=\left(\begin{array}{c}
1 \\
\mathrm{x}_{3} \\
-\frac{\left[\begin{array}{c}
\Gamma_{\mathrm{d}} \exp \left((1+\alpha) \mathrm{x}_{2}\right)+\Gamma_{\mathrm{r}}+ \\
\frac{(1+\alpha) \mathrm{p}_{\mathrm{e}_{0}}}{\mathrm{n}} \exp \left(\frac{(1+\alpha) \mathrm{x}_{2}}{\mathrm{n}}\right)\left(\mathrm{x}_{3}\right)^{2}
\end{array}\right]}{\left(1+\mathrm{p}_{\mathrm{e}_{0}} \exp \left(\frac{(1+\alpha) \mathrm{x}_{2}}{\mathrm{n}}\right)\right)}
\end{array}\right) \\
& =\left(\begin{array}{l}
\Psi_{1}\left(\mathrm{x}_{1}, \mathrm{x}_{2}, \mathrm{x}_{3}\right) \\
\Psi_{2}\left(\mathrm{x}_{1}, \mathrm{x}_{2}, \mathrm{x}_{3}\right) \\
\Psi_{3}\left(\mathrm{x}_{1}, \mathrm{x}_{2}, \mathrm{x}_{3}\right)
\end{array}\right)
\end{aligned}
$$

Together with the initial conditions: 


$$
\left(\begin{array}{l}
\mathrm{x}_{1}(-1) \\
\mathrm{x}_{2}(-1) \\
\mathrm{x}_{3}(-1)
\end{array}\right)=\left(\begin{array}{l}
-1 \\
0 \\
-\lambda_{\mathrm{g}}
\end{array}\right)
$$

Remark 3: $\lambda_{\mathrm{g}}$ is guessed such that the boundary condition $\mathrm{x}_{2}(1)=0$ is satisfied.

$$
\begin{aligned}
& \text { Theorem 2: } \quad \text { For } 0 \leq \alpha \leq \mathrm{N},-1 \leq \mathrm{x}_{1} \leq 1, \\
& 0 \leq \mathrm{x}_{2} \leq \mathrm{M}, \quad \lambda_{\mathrm{g}} \leq \mathrm{x}_{3} \leq-\lambda_{\mathrm{g}}{ }^{*}, \mathrm{M}, \mathrm{N}, \Gamma_{\mathrm{r}}, \Gamma_{\mathrm{d}}, \mathrm{n}, \mathrm{P}_{\mathrm{eo}}>0 \text {, the } \\
& \text { functions } \psi(\mathrm{i}=1,2,3) \text { are Lipschitz continuous. }
\end{aligned}
$$

\section{Proof:}

$\left|\frac{\partial \psi_{1}}{\partial \mathrm{x}_{1}}\right|=0,\left|\frac{\partial \psi_{1}}{\partial \mathrm{x}_{2}}\right|=0,\left|\frac{\partial \psi_{1}}{\partial \mathrm{x}_{3}}\right|=0,\left|\frac{\partial \psi_{2}}{\partial \mathrm{x}_{1}}\right|=0,\left|\frac{\partial \psi_{2}}{\partial \mathrm{x}_{2}}\right|=0,\left|\frac{\partial \psi_{2}}{\partial \mathrm{x}_{3}}\right|=1,\left|\frac{\partial \psi_{3}}{\partial \mathrm{x}_{1}}\right|=0$,

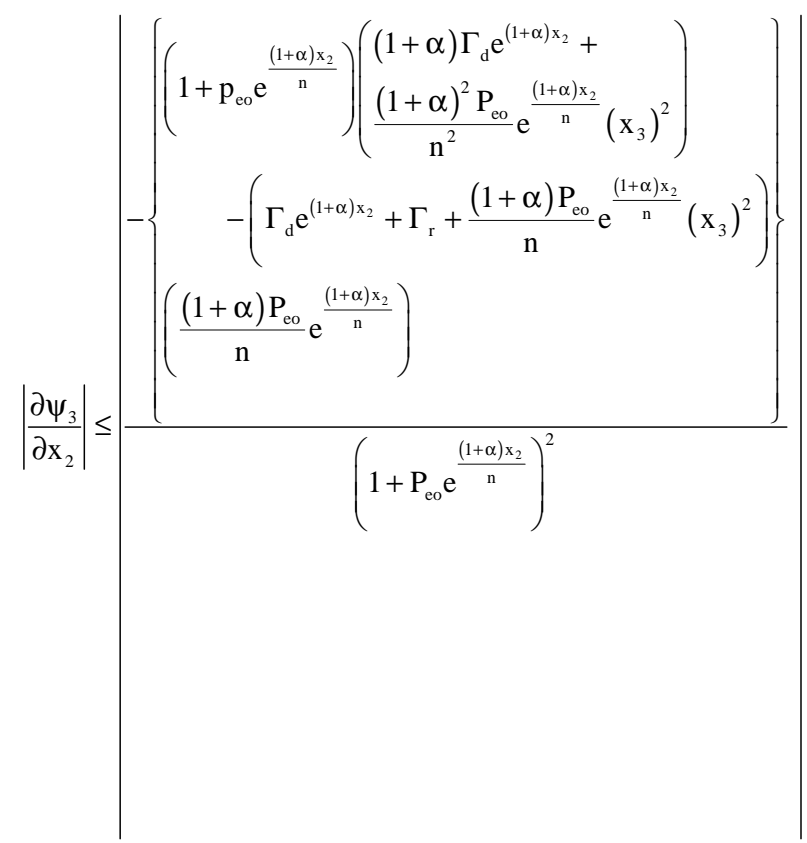

$\left|\frac{\partial \Psi_{3}}{\partial \mathrm{x}_{3}}\right| \leq\left|-\frac{2(1+\alpha) \mathrm{p}_{\mathrm{eo}} \exp \left(\frac{(1+\alpha) \mathrm{x}_{2}}{\mathrm{n}}\right)\left(\mathrm{x}_{3}\right)}{\mathrm{n}\left(1+\mathrm{p}_{\mathrm{eo}} \exp \left(\frac{(1+\alpha) \mathrm{x}_{2}}{\mathrm{n}}\right)\right)}\right|$

$\frac{\partial \psi_{i}}{\partial x_{j}}, i, j=1,2,3$ are bounded since there exists a

Lipschitz constant $\mathrm{K}>0$ such that:

$$
\left|\frac{\partial \psi_{\mathrm{i}}}{\partial \mathrm{x}_{\mathrm{j}}}\right| \leq \mathrm{K}, \quad \mathrm{i}, \mathrm{j}=1,2,3
$$

Hence $\psi_{\mathrm{i}}\left(\mathrm{x}_{1}, \mathrm{x}_{2}, \mathrm{x}_{3}\right), \mathrm{i}=1,2,3$ are Lipschitz continuous and so (19) satisfying (20) is Lipschitz continuous.

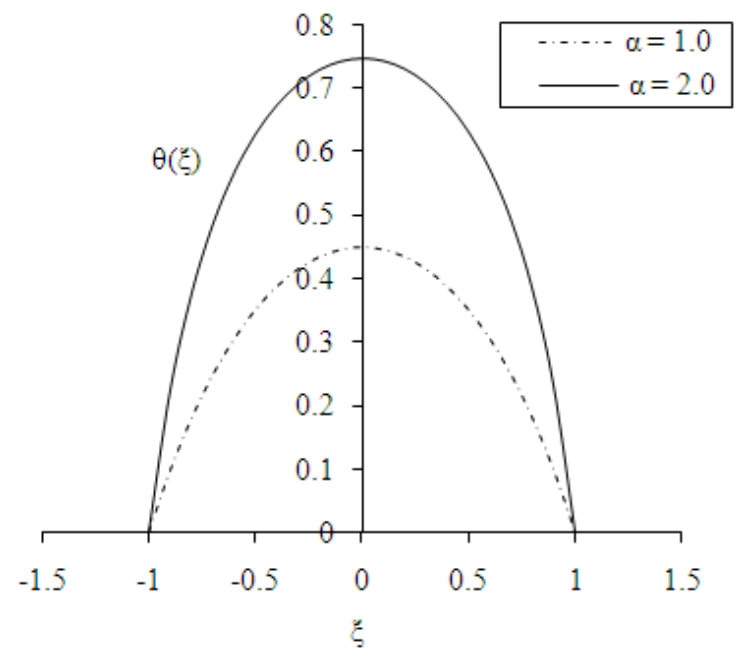

Fig. 3: Steady state temperature profile for fixed values of $\mathrm{h}=0.1 ; \mathrm{P}_{\mathrm{e}}=1.0 ; \Gamma_{\mathrm{d}}=0.9 ; \Gamma_{\mathrm{r}}=0.4 ; \mathrm{n}=1$ and various values of a

Proof of theorem 1: The existence of Lipschitz constant in the proof of theorem 2 implies the existence of unique solution of problem (19) which satisfies (20). And this implies the existence of unique solution of problem (16) satisfying the conditions (17).

The numerical result by shooting method through a computer programme written in Pascal language of problem (16) subject to (17) is presented in the Fig. 3:

For $\mathrm{p}_{\mathrm{eo}} \exp \left(\frac{(1+\alpha) \theta}{\mathrm{n}}\right) \ll<1$

the steady state problem (15) becomes:

$$
\frac{\mathrm{d}^{2} \theta}{\mathrm{d} \xi^{2}}+\Gamma_{\mathrm{d}} \mathrm{e}^{(1+\alpha) \theta}+\Gamma_{\mathrm{r}}=0
$$

Together with the boundary conditions (17).

The system of Eq. 19 becomes:

$$
\left(\begin{array}{l}
\mathrm{x}_{1} \\
\mathrm{x}_{2} \\
\mathrm{x}_{3}
\end{array}\right)=\left(\begin{array}{c}
1 \\
\mathrm{y}_{3} \\
-\Gamma_{\mathrm{d}} \mathrm{e}^{(1+\alpha) \mathrm{y}_{2}}-\Gamma_{\mathrm{r}}
\end{array}\right)
$$

The problem (23) subject to condition (20) is solved by shooting method in which the value of $\lambda_{\mathrm{g}}$ in is guessed such that the boundary condition $\mathrm{x}_{2}(1)=0$. The numerical result as obtained through a computer programme written in Pascal language, is presented in the Fig. 4. 


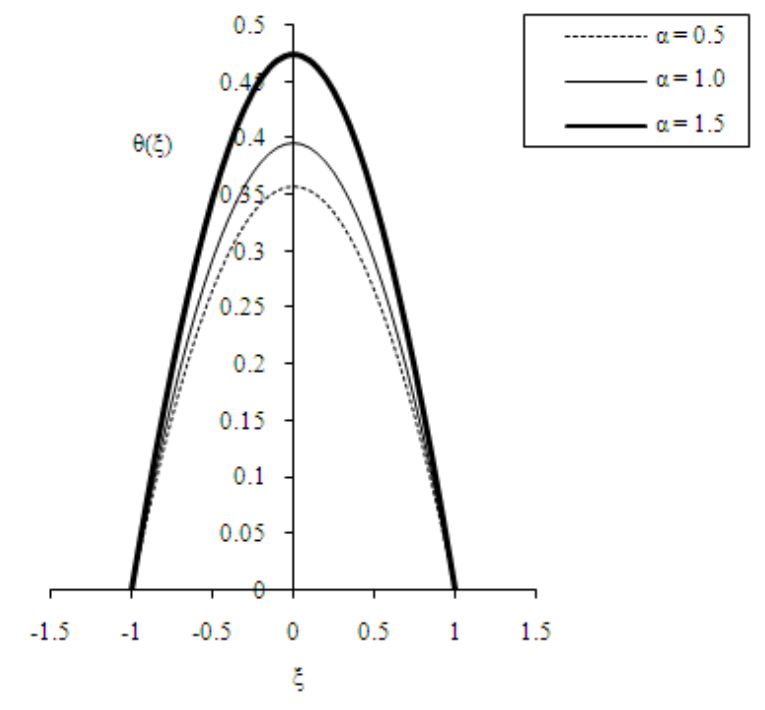

Fig. 4: Steady state temperature profile for some $\alpha>0$

\section{RESULTS AND DISCUSSION}

Results have shown that activation energies ratio has considerable effect on the maximum temperature and blow up.

Figure 1 illustrates the temperature profile for the unsteady reaction. It is observed that as $\alpha$ increases from 0.5 to 0.25 , the maximum temperature also rises. This implies that more heat is released as the activation energies ratio is increased.

In the homogenous reaction, the Eq. 11 and 12 are the respective ignition temperature and blow up criterion under the assumption that no heat is generated from the decay of radioactive substances but from $\mathrm{GD}\left(\Gamma_{\mathrm{r}}=0, \Gamma_{\mathrm{d}} \neq 0\right)$. It is observed from Fig. 2 that as $\alpha$ increases from $0.5-1.5$, the ignition temperature increases and the blow up time reduces. The implication of these results is that explosion occurs quickly as the activation energy ratio is increased. The Eq. 13 and 14 are respectively the ignition temperature and ignition time of the homogenous reaction when heat is also generated from the decay of radioactive substance. A similar effect of activation energy ratio $\alpha$ is experienced in this case.

In the steady state reaction, the proofs of theorems 1 and 2 established the criteria for the existence of unique steady state solution. It is observed from Fig. 3 that an increase in $\alpha$ from 1 to 2 , increases the maximum temperature reaction. The steady state problem was considered for $\mathrm{p}_{\mathrm{eo}} \exp \left(\frac{(1+\alpha) \theta}{\mathrm{n}}\right)<1, \quad$ that is, the diffusion length is much longer than the system size. Figure 4 illustrates the solution of the resulting problem (22) subject to condition (20). The result also follows the previous steady state solution as shown in Fig. 3.

\section{CONCLUSION}

In conclusion, results have shown that activation energies ratio has appreciable effect on thermal explosion in the interior of the earth since it has different implications in terms of heat release. The criteria for which blow up occurs in the homogenous reactions, have equally been established. This result clearly indicates that activation energy ratio $\alpha$ plays catalytic role in the thermal explosion that occurs in the interior of the earth.

\section{ACKNOWLEDGEMENT}

The researcher appreciates useful suggestions and contributions of Professor R.O. Ayeni and the thoughtful comments of the referees.

\section{REFERENCES}

Ayeni, R.O., A.O. Popoola and O.J. Fenuga, 2006. Remarks on thermal explosions in the early evolution of the Earth. J. Nigerian Assoc. Math. Phys., 10: 69-70. ISSN: 1116-4336

Buckmaster, J.D., G.S.S. Ludford and J.D. Buckmaster, 2008. Theory of Laminar Flames. Cambridge University Press Cambridge, ISBN: 0521091926, pp: 280.

Barenblatt, G., 1985. Mathematical Theory of Combustion and Explosion. 1st Edn., Springer, ISBN-10: 0306109743, pp: 597.

Kannan, K. and M. Udayakumar, 2009. Modeling of nitric oxide formation in single cylinder direct injection diesel engine using diesel-water emulsion. Am. J. Applied Sci., 6: 1313-1320. DOI: 10.3844/ajassp.2009.1313.1320

McDonald, W.J., 2005. The anatomy of a volcano, earth quake and tsunami. Researcher, 1: 25-28. http://www.sciencepub.org/researcher/0101/04_04 75_McDonald_tsunami.pdf

Olajuwon, B.I. and A.O. Popoola, 2006. On self similar solution of non-linear diffusion equation with convection term. J. Math. Stat., 2: 453-456. www.unaab.edu.ng/attachments/1538_on\%20self\% 20similatr.PDF

Vityazev, A.V., 2004. Thermal explosions in the early evolution of the earth. Combustion, Exp. Shock Waves, 40: 720-723. DOI: 10.1023/B:CESW.0000048278.50523.7f 